\title{
P01-65
}

\section{CHILDREN OF BACCHUS - WITHDRAWAL IN THE ER}

\section{Roque, A. Craveiro}

Department of Psychiatry, Coimbra University Hospitals, Coimbra, Portugal

Through the ages, Portugal's History, geography, industry and mysticism are intertwined with viniculture. Legends proclaim Lusus the founding father of its inhabitants, who answer to this day to the designation of "Lusos". Lusus was said to be a companion of Bacchus, the Roman God of Wine. Portugal was the $7^{\text {th }}$ major alcohol consumer, according to data by the world Drink Trends 2005. Facing these numbers, it is fairly understood the morbidity and lethality potential of multi-organic diseases, neurologic entities, accidents, suicides, and familial disfunction. Alcoholic Delirium may be caused by alcohol withdrawal, or by a sudden increase in consumption, or phenomena where tolerance to alcohol is diminished. These complex states are affluent in symptomatology, which can evolve to critical life threatening stages.

Objective: The authors' aim is to present a clinical case of Delirium by alcoholic withdrawal.

Methods: The authors undertake a revision of this topic in the literature and clinical files review.

Conclusions: Delirium is not uncommon in Portuguese emergency rooms, though often misdiagnosed. The knowledge tools should be shared by other specialities besides Psychiatry or Liaison Mental Health for treatment may be life-saving. After crisis, the treatment should proceed, based on maintaining abstinence by medication and therapy. 